\title{
Study of statistical data on the composition of electric distribution networks on the example of a Kaluga region district
}

\author{
V.E. Bolshev ${ }^{1,}$, A.V. Vinogradov ${ }^{1}$, A.V. Vinogradova ${ }^{1}$, A.V. Bukreev ${ }^{1}$, and S.R. Khasanov ${ }^{2}$ \\ ${ }^{1}$ Federal Scientific Agroengineering Center VIM, 5 1st InstitutskyProezd, Moscow, 109428, Russia \\ ${ }^{2}$ Kazan State Power Engineering University, 51 Krasnoselskaya St., Kazan, 420066, Russia
}

\begin{abstract}
Sustainable operation of the power grid complex is impossible without reliable and high-quality operation of 10/0.4 kV electrical distribution networks, which are the final link in the system for providing consumers with electric energy and are in direct interaction with a specific consumer. The study of statistical information on the composition of distribution networks makes it possible to draw conclusions about electrical network state, to implement recommendations for their development and to compare distribution electrical networks in different regions. This information is especially relevant for analyzing the reliability of power supply to consumers connected to the considered electrical distribution networks. Such indicators of network structure as the length of electric transmission lines of different voltages and power transmission schemes are studied. It also analyzes the number of damages in networks, the causes of these damages, data on the time of planned and emergency outages. This paper considers the structure of 10/0.4 $\mathrm{kV}$ electrical distribution networks located on the territory of one of the districts of the Kaluga region. The sample for distribution networks was: 1190 overhead transmission lines and 536 transformer substations. Consumers in the district are 21671 subscribers of individuals and 1986 subscribers of legal entities, that is, a total of 23657 metering points. On the lines of $0.4 \mathrm{kV}$ and $10 \mathrm{kV}$, the percentage of their isolated design was revealed. The share of single-transformer and two-transformer versions of transformer substations is analyzed.
\end{abstract}

\section{Introduction}

The study of statistical data on the length, composition of electrical networks, the number and nature of failures in them allows further analysis of power supply system reliability and propose solutions to improve it [1]-[4]. Reliability analysis can be carried out in accordance with known methods [5]-[7]. Moreover, the documents regulating these indicators [8] are outdated and do not reflect the change in reliability indicators characteristic of existing networks. In recent years, the reliability of electrical distribution networks has been growing in connection with the introduction of new types of materials and equipment [9]-[11].

\section{Materials and Methods}

The electrical networks of the Kondovsky Distribution Zone were analyzed. On the analyzed territory there are 1190 overhead electric transmission lines (ETLs) with a total length of $1815.6 \mathrm{~km}$, including 76 ETLs of $10 \mathrm{kV}$ with a length of $886.78 \mathrm{~km}$ and 1114 ETLs of $0.4 \mathrm{kV}$ with a length of $928.85 \mathrm{~km}$. Also, in the region there are 536 transformer substations with an installed capacity of $112.08 \mathrm{MW}$, including $516 \mathrm{pcs}$ with one power transformer with a higher voltage of $10 \mathrm{kV}, 20$ pcs with two $10 \mathrm{kV}$ transformers. Consumers in the district are
21671 subscribers of individuals and 1986 subscribers of legal entities, that is, a total of 23657 metering points.

\section{Results and discussions}

The analysis showed that $10 \mathrm{kV}$ protected lines is made with an Aerial bundled cables ABC-3 having the length of $183.29 \mathrm{~km}$. It is $20.7 \%$ of the total. The rest of the 10 $\mathrm{kV}$ lines are made with uninsulated wires (aluminum conductor steel reinforced - ACSR or all-aluminum-alloy conductor - AAAC).

$0.4 \mathrm{kV}$ overhead power lines of Kondrovsky power networks in insulated version have a length of 363.93 $\mathrm{km}$. They are made with self-supporting insulated wire, mainly of the ABC-2 type, which makes $41.25 \%$ of the total.

$10 / 0.4 \mathrm{kV}$ transformer substations (TS) in the amount of 536 pieces are presented in the majority of onetransformer, which is typical for rural areas. There are only 20 two-transformer substations. The power of the installed transformers ranges from $15 \mathrm{kVA}$ to $1000 \mathrm{kVA}$. All of them are oil-cooled transformers. There are the mainly used transformer types: oil-filled transformer (OFT) and oil-filled waterproofed transformer (OFWT). TS are for the most part of metal kiosk type, less mast. Recently, the construction of pillar TS (PTS) has been practiced.

*Corresponding author: vadimbolshev@ gmail.com 
Table 1.Damages to electrical networks.

\begin{tabular}{|c|c|c|c|c|c|c|c|c|c|}
\hline \multirow{2}{*}{ Name } & \multicolumn{3}{|c|}{$\mathbf{0 . 4} \mathbf{~ k V}$} & \multicolumn{3}{c|}{$\mathbf{1 0 ~ k V}$} & \multicolumn{3}{c|}{ TS } \\
\cline { 2 - 11 } & $\mathbf{2 0 1 6}$ & $\mathbf{2 0 1 7}$ & $\mathbf{2 0 1 8}$ & $\mathbf{2 0 1 6}$ & $\mathbf{2 0 1 7}$ & $\mathbf{2 0 1 8}$ & $\mathbf{2 0 1 6}$ & $\mathbf{2 0 1 7}$ & $\mathbf{2 0 1 8}$ \\
\hline Number of failures, pcs & 180 & 62 & 54 & 124 & 91 & 88 & 42 & 20 & 18 \\
\hline Average power restoration time, $\mathrm{h}$ & 4.6 & 3.1 & 3.1 & 5.5 & 4 & 4 & 7 & 5 & 5 \\
\hline $\begin{array}{c}\text { Scheduled power supply outages } \\
\text { for maintenance and repair, } \mathrm{h}\end{array}$ & 6 & 6 & 6 & 7 & 7 & 7 & 7 & 7 & 7 \\
\hline Total power restoration time, $\mathrm{h}$ & 828 & 192 & 167 & 682 & 364 & 352 & 294 & 100 & 90 \\
\hline
\end{tabular}

Table 2.Used schemes of electric transmission lines of $0.4 \mathrm{kV}$ and $10 \mathrm{kV}$.

\begin{tabular}{|l|c|c|c|c|}
\hline & Trunk & Radial & Ring & Total \\
\hline ETL-10 kV & 17 & 0 & 59 & 76 \\
\hline ETL-0.4 kV & 115 & 769 & 230 & 1114 \\
\hline
\end{tabular}

Table 3.Length of $0.4 \mathrm{kV}$ electric transmission lines.

\begin{tabular}{|l|c|c|c|c|c|c|c|c|c|}
\hline Length of power lines, $\mathbf{k m}$ & $\mathbf{0 - 0 . 5}$ & $\mathbf{0 . 5 - 1}$ & $\mathbf{1 - 1 . 5}$ & $\mathbf{1 . 5 - 2}$ & $\mathbf{2 - 2 . 5}$ & $\mathbf{2 . 5 - 3}$ & $\mathbf{3 . 5 - 4}$ & $\mathbf{4 - 4 . 5}$ & $\mathbf{4 . 5 - 5}$ \\
\hline Number of power lines, pcs & 160 & 293 & 246 & 230 & 98 & 68 & 7 & 7 & 5 \\
\hline
\end{tabular}

Table 4.Number of $10 / 0.4 \mathrm{kV}$ transformer substations connected to $10 \mathrm{kV}$ power lines.

\begin{tabular}{|l|c|c|c|c|c|}
\hline Number of TS, pcs & $\mathbf{0 - 5}$ & $\mathbf{5 - 1 0}$ & $\mathbf{1 0 - 1 5}$ & $\mathbf{1 5 - 2 0}$ & $\mathbf{2 0 - 2 5}$ \\
\hline Number of power lines, pcs & 26 & 26 & 14 & 4 & 6 \\
\hline
\end{tabular}

Table 5.Length of $10 \mathrm{kV}$ electric transmission lines.

\begin{tabular}{|l|c|c|c|c|c|c|c|c|c|}
\hline Length of power lines, $\mathbf{k m}$ & $\mathbf{0 . 5 - 1}$ & $\mathbf{1 - 4}$ & $\mathbf{4 - 8}$ & $\mathbf{8 - 1 2}$ & $\mathbf{1 2 - 1 6}$ & $\mathbf{1 6 - 2 0}$ & $\mathbf{2 0 - 2 4}$ & $\mathbf{2 4 - 2 8}$ & $\mathbf{2 8 - 3 3}$ \\
\hline Number of power lines, pcs & 9 & 12 & 16 & 10 & 8 & 7 & 3 & 6 & 5 \\
\hline
\end{tabular}

According to the technical reports of Kondrovsky Distribution Zone [12] for 2016, 2017, 2018 the analysis of the main indicators of failure rate and damage rate in the networks of the considered area is carried out. The results are shown in Table 1.

The data shown in Table 1 show that the number of failures in electrical networks is decreasing every year. This is due, first of all, to the implementation of programs for the reconstruction of the district's electrical networks, the implementation of new power grid equipment, primarily insulated wires of 0.4 and $10 \mathrm{kV}$ power lines, and power transformers of the OFWT type.

In the course of the work, the analysis of statistical data on the characteristics of electrical networks was carried out on the example of one of the districts of the Kaluga region for 2016 - 2018. The types of used schemes and the length of power lines were analyzed, their statistical characteristics were determined. The results of the analysis are presented below. Table 2 shows the data on the used schemes of the district's electrical networks.

The analysis of the used schemes shows that the majority of $10 \mathrm{kV}$ electric transmission lines are made ring-shaped, have the possibility of redundancy, but this redundancy in the vast majority of cases is manual. 0.4 $\mathrm{kV}$ transmission lines are mainly radial, but there are 230 ring ones, which distinguishes the networks under consideration from networks in some other regions [13], [14]. The use of $0.4 \mathrm{kV}$ ring ETLs increases the reliability of power supply to consumers.

Table 3 shows the data on the distribution of $0.4 \mathrm{kV}$ power lines by the length. $4 \mathrm{kV}$ transmission lines have a length, in most cases, up to $1.5-2 \mathrm{~km}$, however, quite a lot oftransmission lines (more than 70 pcs) have a length of more than two kilometers, which negatively affects reliability. It should be noted that power lines with a length of more than $1 \mathrm{~km}$ have problems not only with reliability, but also with ensuring the sensitivity of their protection against single-phase short circuits

Table 4 shows the data on the distribution of $10 \mathrm{kV}$ power transmission lines by the number of $10 / 0.4 \mathrm{kV}$ transformer substations connected to them.

Statistical data show that there are $10 \mathrm{kV}$ transmission lines, a sufficiently large number of 10/0.4 of $\mathrm{kV}$ transformer substations are connected to. For example, there are six $10 \mathrm{kV}$ transmission lines with more than 20 connected transformer substations. This leads to the fact that in case of failure to a $10 \mathrm{kV}$ power transmission line, a large number of consumers are turned off. Also, during scheduled maintenance of these power lines, an unjustifiably large number of consumers suffer power supply interruptions.

Table 5 presents data on the length of $10 \mathrm{kV}$ power transmission lines.

Most of the $10 \mathrm{kV}$ transmission lines have a length not exceeding $16 \mathrm{~km}$. At the same time, there are also longer ETLs, which indicates the need for their reconstruction, enlargement in order to increase reliability.

Tables 6 and 7 show the causes of damage to overhead lines with a voltage of $0.4 \mathrm{kV}$ and $10 \mathrm{kV}$.

Analysis of the types and amount of damage in the study area showed that the main causes of damage to overhead lines are collapsing and breaking wires, thunderstorm insulation overlaps, wind loads, weakening of the strength of support parts, etc. Damage to overhead 
Table 6.Causes of damages to the $0.38 \mathrm{kV}$ electric transmission lines.

\begin{tabular}{|l|c|c|c|c|c|c|}
\hline \multirow{2}{*}{ Damage causes } & \multicolumn{3}{|c|}{$\begin{array}{c}\text { Amount of total damage, pcs. } \\
\text { (byyears) }\end{array}$} & \multicolumn{2}{c|}{$\begin{array}{c}\text { Relation to the total number of } \\
\text { damages, \% (by years) }\end{array}$} \\
\cline { 2 - 7 } & $\mathbf{2 0 1 6}$ & $\mathbf{2 0 1 7}$ & $\mathbf{2 0 1 8}$ & $\mathbf{2 0 1 6}$ & $\mathbf{2 0 1 7}$ & $\mathbf{2 0 1 8}$ \\
\hline Wirebreakage & 17 & 4 & 5 & $9.4 \%$ & $6.4 \%$ & $9.3 \%$ \\
\hline Cross of wires & 46 & 9 & 4 & $25.5 \%$ & $14.5 \%$ & $7.4 \%$ \\
\hline Fall of trees & 28 & 7 & 3 & $15.6 \%$ & $11.3 \%$ & $5.5 \%$ \\
\hline Tripping circuit breakers / fuse blow & 74 & 36 & 37 & $41.2 \%$ & $58.1 \%$ & $68.5 \%$ \\
\hline Othercauses & 15 & 6 & 5 & $8.3 \%$ & $9.7 \%$ & $9.3 \%$ \\
\hline Total & $\mathbf{1 8 0}$ & $\mathbf{6 2}$ & $\mathbf{5 4}$ & $\mathbf{1 0 0}$ & $\mathbf{1 0 0}$ & $\mathbf{1 0 0}$ \\
\hline
\end{tabular}

Table 7.Causes of damages to the $10 \mathrm{kV}$ electric transmission lines.

\begin{tabular}{|l|c|c|c|c|c|c|}
\hline \multirow{2}{*}{ Damage causes } & \multicolumn{3}{|c|}{$\begin{array}{c}\text { Amount of total damage, pcs. } \\
\text { (byyears) }\end{array}$} & \multicolumn{3}{c|}{$\begin{array}{c}\text { Relation to the total number of } \\
\text { damages, \% (by years) }\end{array}$} \\
\cline { 2 - 7 } & $\mathbf{2 0 1 6}$ & $\mathbf{2 0 1 7}$ & $\mathbf{2 0 1 8}$ & $\mathbf{2 0 1 6}$ & $\mathbf{2 0 1 7}$ & $\mathbf{2 0 1 8}$ \\
\hline $\begin{array}{l}\text { Failure of insulation of poles, disconnectors } \\
\text { (visible damage) }\end{array}$ & 54 & 36 & 29 & $43.6 \%$ & $39.6 \%$ & $32.9 \%$ \\
\hline Fall of trees and branches (Cross of wires) & 37 & 19 & 21 & $29.8 \%$ & $20.8 \%$ & $23.8 \%$ \\
\hline $\begin{array}{l}\text { Undetected causes } \\
\text { (arc overlapping insulation during lightning } \\
\text { and other overvoltage, eliminated by the } \\
\text { action of ACR or when turned on } \\
\text { manually) }\end{array}$ & 22 & 31 & 32 & $17.7 \%$ & $34.1 \%$ & $36.4 \%$ \\
\hline $\begin{array}{l}\text { Damage to PTL equipment by a person } \\
\text { (collision of a vehicle with a utility pole) }\end{array}$ & 11 & 5 & 6 & $8.9 \%$ & $5.5 \%$ & $6.9 \%$ \\
\hline Total & $\mathbf{1 2 4}$ & $\mathbf{9 1}$ & $\mathbf{8 8}$ & $\mathbf{1 0 0 \%}$ & $\mathbf{1 0 0 \%}$ & $\mathbf{1 0 0 \%}$ \\
\hline
\end{tabular}

lines is possible under normal operating conditions due to: increasing the actual electrical loads calculated values; defects arising from the manufacture of poles, wires, insulators; violation of the rules for the installation and construction of overhead lines; shortcomings of operation, etc.

Comparison with statistical data from other regions shows that, in general, the causes of damage are similar both in composition and in percentage [13], [14]. This makes it possible to use the same approaches as in other regions to increase the reliability of distribution electric networks, thus increasing the efficiency indicators of the power supply system of consumers as a whole [15], [16]. The priority of these measures is the downsizing of power lines, the use of automatic sectionalizing of power lines, the use of insulated wires [13].

\section{Conclusion}

During the work, the analysis of statistical data of electrical networks of one of the districts of the Kaluga region for 2016 - 2018 was carried out. Analysis of the used schemes of $10 \mathrm{kV}$ and $0.4 \mathrm{kV}$ electric transmission lines shows that most of $10 \mathrm{kV}$ transmission lines are made ring-shaped with the use of manual sectionalizing. $0.4 \mathrm{kV}$ ETLs are mainly radial, there are ring ones.

The length of $0.4 \mathrm{kV}$ transmission lines is in most cases more than recommended. A large proportion of the lines have a length of more than $1.5 \mathrm{~km}$, which negatively affects power supply reliability.

The length of $10 \mathrm{kV}$ transmission lines for most lines is less than $16 \mathrm{~km}$, although there are a number of transmission lines over $24 \mathrm{~km}$ long. There are $10 \mathrm{kV}$ transmission lines, a sufficiently large number of $10 / 0.4$ $\mathrm{kV}$ transformer substations are connected to. It leads to the fact that a large number of consumers are disconnected in case of failure to a $10 \mathrm{kV}$ transmission line.

The most common causes of failures to transmission lines of both $10 \mathrm{kV}$ and $0.4 \mathrm{kV}$ are similar to the causes of failures to power lines in other regions of Russia. They are: cross and breakage of wires, arc overlapping insulation during lightning, fall of trees, strength weakening of utility poles, etc. It allows recommending a number of measures for the Kaluga region to improve the reliability of distribution networks, applicable in other regions.

\section{References}

[1] A. Vinogradov, et al., Analysis of the Power Supply Restoration Time after Failures in Power Transmission Lines, Energies 2020 13, 11, 2736 (May 2020) DOI: 10.3390/EN13112736.

[2] A. Vinogradov, et al., Methods of Reducing the Power Supply Outage Time of Rural Consumers, in Renewable Energy and Power Supply Challenges for Rural Regions, V. Kharchenko, P. Vasant (Eds.) (Hershey, PA, USA, IGI Global, 2019) 370392 DOI: 10.4018/978-1-5225-9179-5.ch015

[3] C. Su, Z. Hu, Reliability assessment for Chinese domestic wind turbines based on data mining techniques, Wind Energy 21, 3, 198209 (March 2018) DOI: $10.1002 /$ we. 2155 
[4] E.I. Gracheva, O.V Fedorov, Forecasting Reliability Electrotechnical Complexes of In-Plant Electric Power Supply Taking into Account Low-Voltage Electrical Apparatuses, in 2019 International Conference on Industrial Engineering, Applications and Manufacturing (ICIEAM), 1-5 (March 2019) DOI: 10.1109/ICIEAM.2019.8743057

[5] Q. Wang, X. Zhang, R. Tian, Y. Yang, and A. Antonios, Reliability evaluation of distribution network using big data technology [Electronic resource], J. Mine Vent. Soc. South Africa 73, 1, 4347 (2020) Available at: https://www.scopus.com/inward/record.uri?eid=2s2.0-

$85081789612 \&$ partnerID $=40 \&$ md5=aa9d216590d 8 c8d07799de9074f4f42f

[6] O. Florencias-Oliveros, J.-J. González-de-la-Rosa, A. Agüera-Pérez, J.-C. Palomares-Salas, Reliability Monitoring Based on Higher-Order Statistics: A Scalable Proposal for the Smart Grid, Energies 12, 1, 55 (December 2018) DOI: 10.3390/en12010055

[7] C. Sun, X. Wang, Y. Zheng, F. Zhang, A framework for dynamic prediction of reliability weaknesses in power transmission systems based on imbalanced data, Int. J. Electr. Power Energy Syst. 117, 105718 (May 2020) DOI: 10.1016/j.ijepes.2019.105718

[8] RD 34.20.574, Ukazaniya po primeneniyu pokazatelej nadezhnosti e`lementov e`nergosistem i raboty` e`nergoblokov $\mathrm{s}$ paroturbinny`mi ustanovkami [Guidance document 34.20.574 Instructions on the application of reliability indicators for power system elements and operation of power units] (1985)

[9] Yang Yi, Power line sensor networks for enhancing power line reliability and utilization (Georgia Institute of Technology, 2011)

[10] T. McDermott, R. Dugan, Distributed generation impact on reliability and power quality inindices, 2002 Rural Electric Power Conference, Papers Presented at the 46th Annual Conference, 02CH37360, 0-7 (2002) DOI: 10.1109/.2002.1002301

[11] V. Bolshev, A. Vinogradov, M. Jasiński, T. Sikorski, Z. Leonowicz, R. Gono, Monitoring the Number and Duration of Power Outages and Voltage Deviations at Both Sides of Switching Devices, IEEE Access 8, 137174-137184 (2020) DOI: $10.1109 /$ ACCESS.2020.3011836

[12] Kondrovsky Distribution Zone, Tekhnicheskie otchety Kondrovskogo REHS [Technical reports of Kondrovsky Distribution Zone for the years]

[13]A. Vinogradov, A. Vinogradova, V. Bolshev, Analysis of the quantity and causes of outages in LV/MV electrical grids, CSEE J. Power Energy Syst., $\quad 1-7 \quad$ (2020) DOI: 10.17775/CSEEJPES.2019.01920

[14]A. Vinogradov, A. Vasiliev, A. Semenov, A. Sinyakov, V.E. Bolshev, Analiz vremeni pereryvov v energosnabzhenii sel'skikh potrebiteley I metodov yego snizheniya zaschet monitoringa tekhnicheskogo sostoyaniya liniy elektroperedach, Bull. All-Russian Inst. Electrif. Agric. 2, 27, 3-11 (2017)

[15]A. Vinogradov, A. Vasiliev, V. Bolshev, A. Semenov, M. Borodin, Time factor for determination of power supply system efficiency of rural consumers, in Handbook of Research on Renewable Energy and Electric Resources for Sustainable Rural Development, V. Kharchenko, P. Vasant (Eds.) (Hershey, PA, USA, IGI Global, 2018) 394-420 DOI: 10.4018/978-1-5225-38677.ch017

[16]A. Vinogradov, A. Vinogradova, V. Bolshev, Analysis of the Major Constituents of the Power Supply System Efficiency for Rural Consumers, IETE J. Res., 1-9 (June 2020) DOI: $10.1080 / 03772063.2020 .1782782$ 